\title{
Accountantscontrolerisico en tolerantie in onderlinge samenhang bij een (interne) accountantsdienst
}

\author{
J. H. van Barneveld \\ en L. Y. F. M. van Densen
}

\section{Inleiding}

De betreffende Accountantsdienst heeft als belangrijkste opdracht de controle van de geconsolideerde jaarrekening, uitmondend in een (interne) accountantsverklaring. De eigen vaktechnische verantwoordelijkheid, alsmede het in stand houden van een goede afstemming met de externe accountant, noodzaken de Accountantsdienst om ontwikkelingen op het vakgebied bij te houden en zonodig over te nemen.

Dit geldt ook voor de ontwikkelingen om de vakkundige oordeelsvorming steeds meer te objectiveren en te kwantificeren. Ongeveer drie jaar geleden vormde dit aanleiding om binnen deze dienst een kleine werkgroep te formeren om na te gaan in hoeverre de toen nog in een theoretisch stadium verkerende ideeën praktisch toepasbaar konden worden gemaakt.

Inmiddels is een PC-systeem beschikbaar waarmee toleranties kunnen worden berekend en waarmee uitgaande van een waardering van risicofactoren vervolgens de controlemix kan worden samengesteld. Uitgangspunt hierbij is dat de controlemix wordt samengesteld per te realiseren controledoelstelling.

De afgelopen tijd zijn aan risico-analyse en het begrip accountantscontrolerisico veel publikaties gewijd. Toch is het risico-aspect maar één kant van de medaille. Voor ieder controlemiddel afzonderlijk en voor de controlemix in totaliteit geldt dat de controlebijdrage niet alleen wordt bepaald door de betrouwbaarheid van het controlemiddel maar ook door de nauwkeurigheid (tolerantie) waarmee fouten kunnen worden gesignaleerd.

Probleem hierbij is hoe deze factoren per controlemiddel te waarderen en hoe de afzonderlijke waarden te combineren ten einde vast te stellen dat de uiteindelijk gewenste betrouwbaarheid en tolerantie is gehaald. In dit artikel zal de aan de toepassing van de Accountantsdienst ten grondslag liggende 'steekproefequivalenten-methode' worden geïntroduceerd.

Hiermee kunnen de aan de afzonderlijke controlemiddelen toegekende risico's en toleranties worden gecombineerd ter vaststelling dat met de controlemix aan de doelstelling van de controle is voldaan.

\section{Accountantscontrolerisico}

Accountantscontrolerisico $(\mathrm{AR})$ is het risico dat de zorgvuldig arbeidende accountant onbewust een verklaring afgeeft, waarvan de strekking niet overeenstemt met de inhoud van de gecontroleerde verantwoording. Kort gezegd en voor de accountant het belangrijkst: een goedkeurende verklaring bij een foutieve verantwoording. Nadat de accountant zijn controle heeft afgerond, dient het accountantscontrolerisico te zijn geredu-

J. H. van Barneveld en L. Y. F. M. van Densen, registeraccountants, zijn beiden sectorhoofd bij de Interne Accountantsdienst van Nationale Nederlanden N.V. 


\section{MAB}

ceerd tot het door de accountant gewenste niveau.

Het accountantscontrolerisico wordt geacht te zijn opgebouwd uit de volgende componenten:

- inherent risico (IR): het risico op het voorkomen van materiële fouten ongeacht de werking van de administratieve organisatie;

- interne-controle risico (ICR): het risico dat eventuele materiële fouten door de administratieve organisatie en de daarin opgenomen maatregelen van interne controle en beveiliging niet worden opgespoord en gecorrigeerd;

- cijferbeoordelingsrisico (CBR): het risico dat eventuele materiële fouten door de accountant door middel van cijferbeoordeling niet worden opgespoord;

- resterend risico (RR): het risico dat de naast administratieve organisatie en cijferbeoordeling toe te passen overige controlemiddelen (veelal detailwaarnemingen) niet in staat zijn eventuele materiële afwijkingen te signaleren.

Het accountantscontrolerisico wordt bepaald volgens de formule:

formule 1.0

$$
A R=I R \times I C R \times C B R \times R R
$$

Formule 1.0 kan worden getransformeerd in formule 1.1 waarbij links van het 'is gelijk'-teken de componenten staan die onafhankelijk zijn van de toe te passen controlemiddelen en rechts de daarvan afhankelijke risicocomponenten:

formule 1.1

$$
\frac{\mathrm{AR}}{\mathrm{IR}}=\mathrm{ICR} \times \mathrm{CBR} \times \mathrm{RR}
$$

Uit formule 1.1 blijkt dat het door middel van de controlemix, bestaande uit administratieve organisatie, cijferbeoordeling en overige controlemiddelen, te reduceren risico gelijk is aan het gewen- ste accountantscontrolerisico gecorrigeerd met het aanwezig geachte inherent risico.

Binnen het risico-analyseproces worden achtereenvolgens de volgende stappen doorlopen:

- vaststellen van het maximaal aanvaardbaar geachte accountantscontrolerisico;

- inschatten van het inherent risico;

- toekennen van risico aan de controlemiddelen administratieve organisatie en cijferbeoordeling;

- vaststellen in hoeverre nog aanvullende zekerheid dient te worden verkregen uit de overige ter beschikking staande controlemiddelen.

De AR-formule wordt hiervoor in de praktijk als volgt gebruikt:

formule 1.2

$$
\mathrm{RR}=\frac{\mathrm{AR} / \mathrm{IR}}{\mathrm{ICR} \times \mathrm{CBR}}
$$

\section{Tolerantie}

De controle van de jaarrekening zal zodanig moeten zijn ingericht dat, uitgaande van een gedefinieerd accountantscontrolerisico, de accountant fouten die van materiële betekenis zijn zal moeten signaleren. Omgekeerd kan de accountant derhalve een zekere onnauwkeurigheid of tolerantie hanteren.

Terzake doen zich twee problemen voor:

1 hoe wordt de tolerantienorm vastgesteld? en

2 hoe moet de controlemix worden samengesteld opdat de tolerantienorm wordt gerealiseerd?

Binnen de betreffende Accountantsdienst is besloten om de tolerantie uit te drukken in een percentage van het totaal van baten en lasten in absolute zin.

Met andere woorden op het totaal van alle resultaatbeïnvloedende posten, ongeacht het teken. De tolerantie is daarmee minder gevoelig voor wijzigingen in individuele posten dan wanneer deze in een directe relatie staat met het resultaat. De (jaarrekening-)tolerantie wordt vervolgens met 


\section{MAB}

behulp van de volgende formule verdeeld over de individuele baten en lasten (posttoleranties).

formule $2^{1}$
De tolerantie van de administratieve organisatie is gelijk aan de omvang van de niet door de interne controle ontdekte en gecorrigeerde mogelijke fouten. De betreffende Accountantsdienst gaat

jaarrekeningtolerantie \%

posttolerantie $\%=\sqrt{\text { (bedrag indiv. post/som van baten en lasten) }}$

In de volgende stap van het controleproces worden de berekende posttoleranties beoordeeld en zonodig bijgesteld. Reden hiervoor kan zijn dat de posttolerantie een gestelde bovengrens overschrijdt cq. dat de accountant oordeelt dat de gehanteerde controle-aanpak een lagere of hogere tolerantiewaarde rechtvaardigt.

Om te voorkomen dat de jaarrekeningtolerantie door deze aanpassing wordt beïnvloed, wordt het effect van de wijzigingen tegengesteld gecorrigeerd op de posttoleranties van de overige baten en lasten. De jaarrekeningtolerantie blijft hierbij gelijk.

Binnen de grenzen van de aanvaardbaarheid kan op deze wijze de efficiency van de controle worden beinvloed. Door verlaging van de tolerantie van met geringe inspanning te controleren posten kunnen per saldo besparingen worden verkregen omdat de toleranties van de met meer inspanning te controleren posten hierdoor worden verhoogd.

\section{Risico en tolerantie in onderlinge samenhang}

In de definiëring van de risicocomponenten (zie paragraaf 2) wordt het risico telkens gerelateerd aan een nauwkeurigheidscriterium (materiële fouten). Tolerantie (paragraaf 3 ) is de kwantitatieve maatstaf voor wat onder materiële fouten moet worden verstaan.

Het toepassen van de AR-formule (formule 1.0) impliceert dat per risicocomponent hetzelfde materialiteitscriterium wordt gehanteerd. De formule wordt onbruikbaar indien bij de waardering van de risico's verschillende toleranties worden gebruikt. Het is dus noodzakelijk te onderzoeken in hoeverre hetzelfde materialiteitscriterium bij de te onderscheiden controlemiddelen wordt gehanteerd. ervan uit dat een toereikende administratieve organisatie minimaal in staat is om, met een gedefinieerde mate van betrouwbaarheid, fouten groter dan de door de accountant berekende posttolerantie te signaleren en te corrigeren.

De nauwkeurigheid van het controlemiddel cijferbeoordeling wordt bepaald door de omvang van de afwijkingen die kunnen worden gesignaleerd. Deze is afhankelijk van de kwaliteit van de cijferbeoordeling, die mede bepaald wordt door de beschikbaarheid en hardheid van normen. De nauwkeurigheid van de cijferbeoordeling hoeft niet gelijk te zijn, en is dat veelal ook niet, aan de door de accountant berekende posttolerantie.

Op grond van het voorgaande zou nu geconcludeerd moeten worden dat de AR-formule niet bruikbaar is. Immers voor de controlemiddelen administratieve organisatie en cijferbeoordeling worden (veelal) verschillende toleranties gehanteerd.

Bij de betreffende Accountantsdienst is hiervoor een oplossing gevonden, gebaseerd op het principe dat tolerantie en risico onderling uitwisselbaar zijn. Een gegeven dat bij de accountant, die gewend is om met steekproeftoepassingen om te gaan, bekend zal zijn. Er zijn namelijk verschillende combinaties van risico en tolerantie waarbij een even groot aantal steekproeftrekkingen moet worden verricht. ${ }^{2}$

\section{Steekproefequivalentenmethode}

De steekproefequivalentenmethode is gebaseerd op het principe dat tolerantie en risico onderling uitwisselbaar zijn. Door middel van de door de betreffende Accountantsdienst gehanteerde formule $^{3}$ uit de steekproeftheorie kunnen risico en tolerantie worden gecombineerd en kan het 


\section{MAB}

resultaat worden gekwantificeerd in een aantal steekproeftrekkingen of steekproefequivalenten. Het aantal steekproefequivalenten wordt geacht een maatstaf te zijn voor de controlebijdrage.

Voor ieder controlemiddel afzonderlijk kan, met behulp van de steekproefformule, de bijbehorende controlebijdrage worden berekend in steekproefequivalenten. De som van de afzonderlijke controlebijdragen moet uiteindelijk voldoen aan de totaal benodigde controlebijdrage.

Een voorbeeld moge dit verduidelijken:

Accountantscontrolerisico $=2 \%$

Posttolerantie $=1 \%$

In verband met bestaande onzekerheden waardeert de accountant het inherent risico veiligheidshalve op $100 \%$.

Het accountantscontrolerisico gecorrigeerd met het inherent risico bedraagt $2 \% / 100 \%=2 \%$

De totaal vereiste controlebijdrage bedraagt derhalve:

$\log (0,02) / \log (1-0,01)=389$ steekproefequivalenten.

$\mathrm{N}_{\text {controlemix }}{ }^{-} 389$

Op grond van de beoordeelde opzet van de administratieve organisatie en op het bestaan en werking gerichte compliance-controles besluit de accountant in dit geval van de administratieve organisatie gebruik te maken. De aan de administratieve organisatie te ontlenen betrouwbaarheid waardeert hij op 95\% (derhalve een risico van $5 \%$ ). De tolerantie is gelijk aan de posttolerantie (zie paragraaf 4 ) en bedraagt in dit voorbeeld $1 \%$.

De bijdrage van de administratieve organisatie in steekproefequivalenten bedraagt:

$\log (0,05) / \log (1-0,01)=298$ steekproefequivalenten.

$\mathrm{N}_{\mathrm{ao}}=298$

Ervaringen uit het verleden (gesignaleerde fouten) doen de accountant in dit voorbeeld besluiten dat de tolerantie van de cijferbeoordeling $10 \%$ bedraagt. Het risico dat de cijferbeoordeling niet in staat is om fouten groter dan $10 \%$ te signaleren waardeert de accountant op $20 \%$.
In steekproefequivalenten is de bijdrage van de cijferbeoordeling:

$\log (0,20) / \log (1-0,10)=15$ steekproefequivalenten.

$\mathrm{N}_{\mathrm{cb}}=15$

De enige nu nog onbekende is de te leveren bijdrage van de overige controlemiddelen in steekproefequivalenten: $\mathrm{N}_{\text {overig. }}$

Deze is eenvoudig te berekenen met behulp van de volgende formule waarin $N$ voor het aantal steekproefequivalenten staat:

formule 3

$$
N_{\text {controlemix }}=N_{\text {ao }}+N_{c b}+N_{\text {overig }}
$$

Als de accountant besluit om de resterende zekerheid te ontlenen aan een steekproef, dan is de minimale omvang van de steekproef gelijk aan het aantal steekproefequivalenten behorende bij de overige controlemiddelen ofwel in dit voorbeeld 76 trekkingen (onder de veronderstelling dat geen fouten worden gevonden).

Uiteraard is het mogelijk dat nog een combinatie van controlemiddelen wordt toegepast, bijvoorbeeld inlichtingen van de gecontroleerde en steekproefgewijze detailcontrole. In dat geval zal de controlebijdrage van de overige controlemiddelen nader moeten worden verdeeld over die controlemiddelen.

Resumé

\begin{tabular}{lcccc}
\hline & Totaal & Adm. Org. & Cijferb. & Overige \\
\hline Risico & $2 \%$ & $5 \%$ & $20 \%$ & \\
\hline Tolerantie & $1 \%$ & $1 \%$ & $10 \%$ & \\
\hline$N$ & 389 & 298 & 15 & 76 \\
\hline
\end{tabular}

Het zal u opvallen dat geen waarden voor risico en tolerantie zijn ingevuld bij de overige controlemiddelen. Dit is bewust achterwege gelaten omdat hier in principe iedere combinatie van risico en 


\section{MAB}

tolerantie kan worden ingevuld mits deze maar leidt tot een bijdrage aan de controlemix van 76 steekproefequivalenten.

Uitgaande van de posttolerantie van $1 \%$ bedraagt het risico van de overige controlemiddelen $46,6 \%$.

\section{Verband tussen AR-formule en steekproefequivalentenmethode}

In paragraaf 5 is formule 3 gebruikt waarmee de afzonderlijke controle-inspanningen werden getotaliseerd. Deze formule is wiskundig af te leiden van de AR-formule (formule 1.0) ${ }^{4}$.

Gesteld was dat in formule 3 verschillende tolerantiewaarden mochten worden gebruikt.

Op grond van de gesignaleerde uitwisselbaarheid van risico en tolerantie is het mogelijk om een andere tolerantie in te vullen, mits ook de bijbehorende risicowaarde zodanig wordt aangepast dat de uitkomst ( $\mathrm{N}$ of aantal steekproefequivalenten) gelijk blijft.

Ter illustratie:

In het voorbeeld van paragraaf 5 kan uitgaande van het aantal steekproeftrekkingen van 76 en de posttolerantie van $1 \%$ met behulp van de steekproefformule ${ }^{3}$ worden uitgerekend dat het resterend risico $46,6 \%$ bedraagt.

Vervolgens kan met de AR-formule (formule 1.0) worden uitgerekend dat, bij een voor ieder controlemiddel gelijke tolerantie, het cijferbeoordelingsrisico $86 \%$ moet bedragen.

De combinatie van cijferbeoordelingsrisico van $86 \%$ en een posttolerantie van $1 \%$ is gelijk aan de combinatie van $20 \%$ risico en $10 \%$ tolerantie en geeft als resultaat een aantal steekproefequivalenten van 15 .

\section{Conclusies en bevindingen tot dusver}

De eerste ervaringen met het voor de tolerantieberekening en samenstelling van de controlemix ontwikkelde PC-model, gebaseerd op risicoanalyse en de steekproefequivalentenmethode, hebben onder meer de volgende conclusies opgeleverd:
- toepassing leidt tot een toegenomen bewustzijn voor de samenstelling van de controlemix in relatie tot de risico's;

- de steekproefequivalentenmethode komt tegemoet aan het bezwaar dat per controlemiddel verschillende waarden worden toegekend aan risico en tolerantie. Door de omrekening in steekproefequivalenten worden weer vergelijkbare grootheden verkregen;

- na de vertaling in steekproefequivalenten kan per controlemiddel de relatieve bijdrage in de controlemix eenvoudig worden vastgesteld. In het voorbeeld van paragraaf 5 bedragen de relatieve bijdragen:

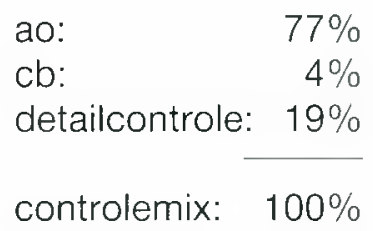

De grote bijdrage van de administratieve organisatie onderstreept nog eens het belang van dit controlemiddel;

- het effect van het (gedeeltelijk) vervangen van een controlemiddel door een ander kan met behulp van de steekproefequivalentenmethode eenvoudig worden vastgesteld en kan daardoor bijdragen aan efficiencyverbetering. Voorbeeld: Indien de tolerantie van de cijferbeoordeling in het voorbeeld van paragraaf 5 kan worden verlaagd tot $5 \%$ en de inspanning daarvoor bedraagt 2 uur dan zal de steekproefomvang verminderen met 16 trekkingen tot 60 trekkingen.

Indien de controle per post 0,5 uur bedraagt dan bedraagt het voordeel 6 uur;

- de beschreven methode van tolerantieberekening en -toerekening aan posten maakt het mogelijk om uitgaande van een gelijkblijvende jaarrekeningtolerantie de individuele posttoleranties te herverdelen en zo de efficiency van de controle te vergroten;

- de methode laat voldoende plaats voor de vaktechnische oordeelsvorming van de individuele accountant met name ten aanzien van de risico-afweging en de beoordeling van de uitkomsten. Vaktechnische beoordeling van de 


\section{MAB}

uitkomsten door de accountant blijft noodzakelijk;

- een uniforme, in een rekenmodel geformuleerde ondersteuning van het controleproces is een belangrijke bijdrage aan de kwaliteitsbeheersing van de controlewerkzaamheden binnen de betreffende Accountantsdienst.

\section{Literatuur}

Dijk RA, J. F. van, 'De betekenis van "materiality" voor de accountantscontrole van de jaarrekening', Maandblad voor Accountancy en Bedrijfseconomie, januari/februari 1989.

NIVRA, 'Accountantscontrolerisico', Nivra geschrift, nummer 49, september 1989.

Wolde RA, J. ten, 'Inherent risico en accountantscontrole', de Accountant, nummer 10, juni 1989.

Zuber, George R., Elliott, Robert K., Kinney, William R., Jr and Leisenring, James J., 'Using materiality in audit planning', Journal of Accountancy, maart 1983.

\section{Noten}

1 Formule 2 is wiskundig af te leiden van de door Zuber, Eliot, Kinney en Leisenring in hun artikel 'Using materiality in audit planning' gehanteerde formule.

2 Ter illustratie:

$\begin{array}{rcr}\begin{array}{r}\text { steekproef } \\ \text { trekkingen }^{3}\end{array} & \text { risico } & \text { tolerantie } \\ 160 & \pm 10 \% & \\ 160 & \pm 20 \% & 1,4 \% \\ 160 & \pm 40 \% & 1,0 \% \\ & & 0,6 \%\end{array}$

3 Formule voor de berekening van het aantal steekproeftrekkingen:

$N=\frac{\log (\text { risico })}{\log (1 \text {-tolerantie })}$

4 Afleiding formule 3 van formule 1.0:

(Ten behoeve van de overzichtelijkheid wordt het inherent risico geacht als correctiepost te zijn verwerkt in het accountantscontrolerisico)

$\mathrm{AR}=\mathrm{ICR} \times \mathrm{CBR} \times \mathrm{RR}$

$\frac{\log A R}{\log (1-\text { tol })}=\frac{\log I C R}{\log (1-\text { tol })}+\frac{\log C B R}{\log (1 \text {-tol })}+\frac{\log R R}{\log (1 \text {-tol })}$
$N_{\text {controlemix }}=N_{a o}+N_{c b}+N_{\text {overig }}$

